\title{
Patient and GP experiences of pathways to diagnosis of a second primary cancer: a qualitative study
}

\author{
Debbie Cavers ${ }^{{ }^{*}}$ (D) , Rhona Duff ${ }^{2}$, Annemieke Bikker ${ }^{1}$, Karen Barnett ${ }^{3}$, Lovney Kanguru4 ${ }^{4}$, David Weller', \\ David H. Brewster ${ }^{1}$ and Christine Campbell ${ }^{1}$
}

\begin{abstract}
Background: More people are surviving a first primary cancer and experiencing a second, different cancer. However, little is known about the diagnostic journeys of patients with second primary cancer (SPC). This study explores the views of patients and general practitioners (GPs) on their experiences of pathways to diagnosis of SPC, including the influence of a previous diagnosis of cancer on symptom appraisal, help-seeking and referral decisions.

Methods: Qualitative interviews with patients with a SPC diagnosis and case-linked GP interviews in a Scottish primary care setting. In-depth face to face or telephone interviews were conducted, underpinned by a social constructionist approach. Interviews were transcribed and Braun and Clarke's thematic analysis undertaken. Three analysts from the research team read transcripts and developed the coding framework using QSR NVivo version 10, with input from a fourth researcher. Themes were developed from refined codes and interpreted in the context of existing literature and theory.

Results: Interviews were conducted with 23 patients (aged 43-84 years) with a SPC diagnosis, and 7 GPs. Five patient themes were identified: Awareness of SPC, symptom appraisal and help-seeking, pathways to diagnosis, navigating the healthcare system, and impact of SPC. GPs interviews identified: experience and knowledge of SPC and referrals and decision-making.

Conclusions: Insights into the pathway to diagnosis of SPC highlights the need for increased awareness of and vigilance for SPC among patients and healthcare providers (HCPs), and emotional support to manage the psychosocial burden.
\end{abstract}

Keywords: Second primary cancer, Qualitative, Pathways to diagnosis, Survivorship, Primary health care, General practice

\section{Background}

The number of people surviving cancer is increasing [1] and, in combination with an ageing population, the incidence of second primary cancers (SPCs) will also inevitably rise [2]. Within the context of cancer survivorship,

\footnotetext{
* Correspondence: Debbie.Cavers@ed.ac.uk

1 Usher Institute of Population Health Sciences, Medical School, University of Edinburgh, Teviot Place, Edinburgh EH8 9AG, UK

Full list of author information is available at the end of the article
}

recurrence and metastatic disease research, there is a small but growing literature on SPC [3-5]. Research on SPC to date has focused on incidence, risk (from environmental, lifestyle and genetic factors), and late treatment effects following a first primary cancer (FPC) e.g. [6-8]. The reported risk of developing SPC among cancer survivors ranges from 1 and 17\% depending on the index cancer site e.g. [7-9]. A West of Scotland cancer registry study reported that among 57,393 cancer survivors, $5 \%$ were diagnosed with SPC

(c) The Author(s). 2021 Open Access This article is licensed under a Creative Commons Attribution 4.0 International License, which permits use, sharing, adaptation, distribution and reproduction in any medium or format, as long as you give appropriate credit to the original author(s) and the source, provide a link to the Creative Commons licence, and indicate if changes were made. The images or other third party material in this article are included in the article's Creative Commons licence, unless indicated otherwise in a credit line to the material. If material is not included in the article's Creative Commons licence and your intended use is not permitted by statutory regulation or exceeds the permitted use, you will need to obtain permission directly from the copyright holder. To view a copy of this licence, visit http://creativecommons.org/licenses/by/4.0/. The Creative Commons Public Domain Dedication waiver (http://creativecommons.org/publicdomain/zero/1.0/) applies to the data made available in this article, unless otherwise stated in a credit line to the data. 
within 5 years of their first diagnosis [10]. SPCs are estimated to account for as much as $16-18 \%$ of total cancer incidence [11-13].

Relatively little is known about pathways to diagnosis of SPC. The Pathways to Treatment Model (see Fig. 1) highlights the complexities of multiple patient factors - including psychological features and prior experiences in influencing symptom appraisal and help-seeking behaviours, which may also be applicable to SPCs [14]. The limited evidence suggests that although fear of a second cancer has been identified as a source of worry and psychosocial distress [4], there is a general lack of awareness regarding risk of SPC [5]. There is a need for greater understanding of differences between diagnostic journeys for recurrence of FPC versus a second, different cancer, and their associated psychological dynamics. There are implications for awareness-raising and, if appropriate, designing behavioural interventions to facilitate early detection of SPC $[4,15]$.

Further, there are challenges for primary care in managing cancer follow-up, and SPCs will be an increasing feature of this care [5, 16-18]. Not enough is known about the impact on primary care of a growing burden of complex disease, including second and subsequent primary cancers [19]. Exploring the extent to which the policy drive for early detection and treatment of cancer applies to SPC in its current form is warranted [2, 20].

Understanding cancer survivors' lived experiences of SPC and their pathways to diagnosis, as well as the perspectives of general practitioners (GPs) managing them, will contribute to the growing evidence base on best practice in cancer survivorship care.

\section{Aims and objectives}

This study aimed to examine: 1) experiences of people diagnosed with SPC, 2) the influence of a previous experience of cancer on the SPC diagnostic pathway, including symptom appraisal and help-seeking, and 3) experiences and challenges of diagnosing SPC from the GP perspective.

\section{Methods}

The study involved a series of in-depth interviews carried out in 2018 with patients diagnosed with SPC in Scotland, and the GPs involved in diagnosing and managing SPCs. The study was based on a social constructionist approach and conducted by a research team comprised of clinical and academic health service researchers experienced in researching pathways to diagnosis and early detection of cancer. This article has followed the COREQ reporting guidelines (see supplementary file 1).

\section{Participants}

Participants were patients who have had a diagnosis of SPC of the four main cancer types (breast, bowel, lung and prostate) within the previous 6 months, where the SPC is defined as a new cancer in the same or a different anatomical site but with different pathology to the FPC [21]. Interviews were also sought with patients' main GPs.

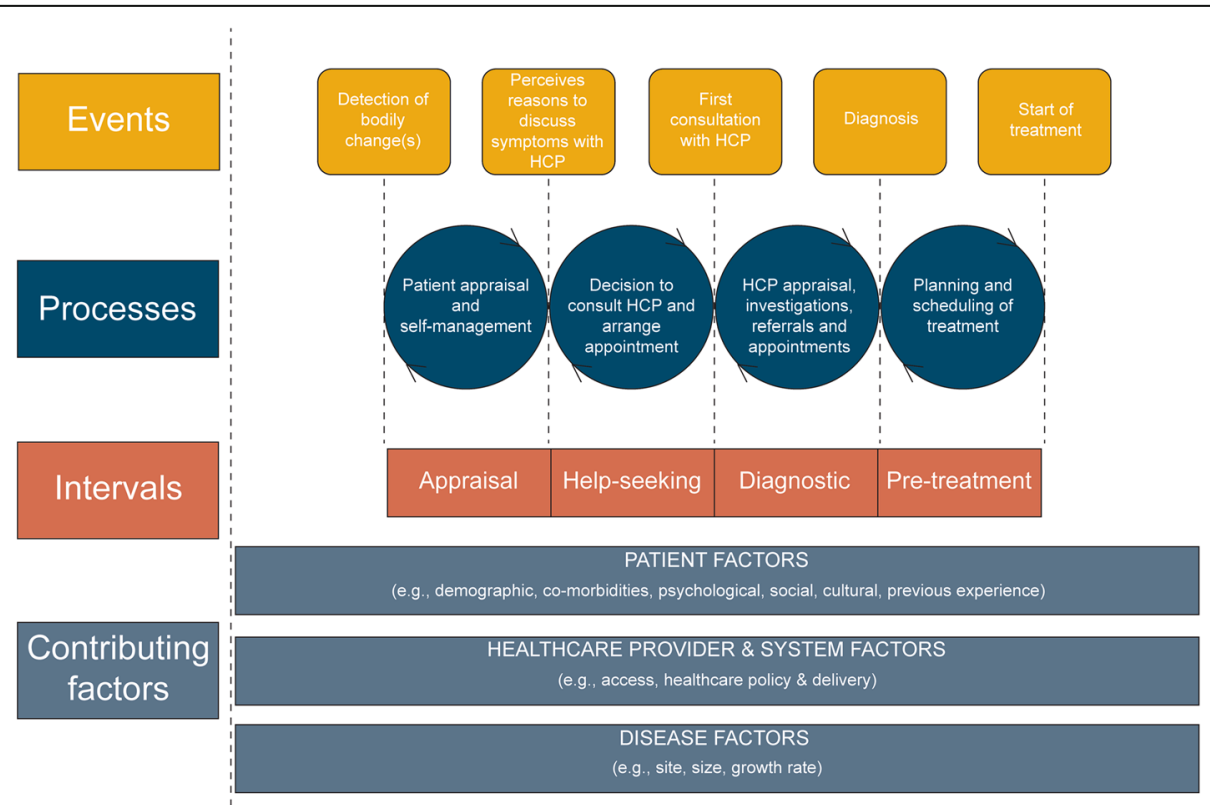

Fig. 1 Pathways to treatment model [14] 


\section{Recruitment and sampling}

Patients were identified from the Scottish Cancer Registry, by NHS staff working for National Services Scotland's Electronic Data Research and Innovation Service (eDRIS). Recruitment packs (information sheet, consent form and reply slip) were sent with a covering letter to eligible patients' GPs to confirm diagnosis and screen for suitability. To protect patient confidentiality, GPs were asked to forward the packs to appropriate patients. Interested patients returned a reply slip and consent form to the researcher $(A B$, an experienced health services and qualitative researcher with a background in social anthropology) who contacted them to build rapport, discuss the study, and arrange an interview. Due to challenges in recruiting this select group, all eligible patients who responded were interviewed. However, the participants were diverse in terms of gender, location and cancer types. No one withdrew from the study. With patient consent, GPs were then invited for interview (see Fig. 2 recruitment process).

\section{Interviews}

Interviews were one-off and semi-structured, using open-ended questions and a patient-centred approach to explore patient experiences of both first and second primary cancer, including psychosocial dimensions of experience and pathways to diagnosis. The topic guide was developed (for this study) in the first instance by $A B$ and refined with input from $D C, C C$ and a patient representative, using their experience of interviewing on the topic of pathway to diagnosis and living with cancer as well as a patient perspective (see supplementary file 2). Written consent was given prior to, and checked before, the interview commencing. Interviews were face to face in patients' own homes, in a university meeting room, or by telephone, lasting approximately $1 \mathrm{~h}$. Participants were aware of the objective of the study and that $A B$ was a health services researcher from a non-medical background. Field notes were taken and used to inform subsequent analysis and aid reflexivity.

Face to face and telephone interviews were carried out with case-linked GPs (including specific discussion of the patient's case if relevant).

\section{Analysis}

All interviews were digitally recorded, transcribed and anonymised before being uploaded to QSR Nvivo version 10 (www.qsrinternational.com). Data were subject to Braun and Clarke's thematic analysis [22]. Transcripts were read by three researchers (RD, DC and CC with additional input from $\mathrm{AB}$, thus ensuring triangulation and rigour in the analytic approach), and re-read for the purposes of familiarisation; looking for emergent and recurrent concepts. Appraisal across data compared and contrasted to establish common codes. Codes were then applied back across the data to ensure that no new codes or concepts were apparent, such that a level of data saturation was reached. In addition, through an iterative process of analysis of patient interviews, no new themes were apparent with subsequent interviews, suggesting a sufficient sample size for thematic saturation, although we acknowledge the limitations of this notion and recognise that the concept of saturation has been problematised in the literature [23]. Limitations of recruitment to GP interviews and subsequent saturation are expanded on in the discussion. Any deviation from core themes was explored and interpreted by the research team and consensus was reached among analysts. Findings were considered, developed and reported as themes in the context of existing theory and research, including the Pathways to Treatment model. Due to time and other resource constraints, a summary of the analysis was not returned to participants for member checking.

\section{Results}

Patient interviews

Of 23 people interviewed, 20 met the final inclusion criteria (see Table 1); 15 women and five men, ranging in age from 43 to 84 years. Time between first and second diagnoses ranged from 1 to 34 years. Ten participants were diagnosed by presenting to primary care with symptom concerns, while the remainder had their cancers detected incidentally, through screening or during specialist follow-up for their FPC. All participants had at least one form of comorbidity.

A number of central themes evident in the data are reported. Additional supporting quotes for some themes relating to patient interviews can be found in Table 2 .

\section{Awareness of SPC}

Overall, there was low awareness among patients about the risk of developing SPC. SPC diagnosis came as a big shock to many,

\section{"It was totally unexpected because I didn't realise that you could have two cancers running at the same time." P11}

Patients were more likely to fear recurrence of their FPC. In some cases, however, there had been such a long interval between their diagnoses that their FPC had receded in significance or, in one case, they had forgotten about it altogether.

SPC was not something that was reportedly discussed with their GP or oncologist during treatment or followup of the FPC and, on the whole, participants did not think it influenced the timeliness of their referral for their SPC (something that was echoed in GP interviews). 
1. eDRIS identified up to 500 patients on the Scottish Cancer Registry and conducts vital status checks.

\section{$\checkmark$}

2. eDRIS sent study documents to the GP and a study pack for forwarding to patients. eDRIS logged details of general practice, patient and date of postage

3. GP forwarded letter and study pack to patient and returned acknowledgement slip to eDRIS. Follow-up by eDRIS if no acknowledgement was received

4. Patient returned consent form and response slip to research team at University of Edinburgh

5. Identified potential participants for interviews. Aim for 30 patient and 15 GP interviews.

$\checkmark$

B. Interviews (up to 30 patients, 15 GPs)

$\checkmark$

B6. Researcher contacts consenting patients and agrees a time for the interview.

B7. Researcher conducts interview (phone or face-to-face). Consent asked to invite their GP for interview

B8. Researcher sends study pack to GPs to invite them for an interview followed up by phone call if no response in 2 weeks.

B9. Researcher organises and conducts interview (phone or face-to-face) with GP.

B10. Transcribe interviews and upload transcripts to qualitative data analysis software for analysis.

Fig. 2 Patient and GP recruitment process 
Table 1 Patient demographics and characteristics of FPC and SPC

\begin{tabular}{|c|c|c|c|c|c|c|c|}
\hline & $\begin{array}{l}\text { Sex/ Age } \\
\text { range }\end{array}$ & $\begin{array}{l}\text { FPC } \\
\text { Diagnosis }\end{array}$ & $\begin{array}{l}\text { Mode of } \\
\text { Detection }\end{array}$ & $\begin{array}{l}\text { Time Interval } \\
\text { FPC /SPC }\end{array}$ & $\begin{array}{l}\text { SPC } \\
\text { Diagnosis }\end{array}$ & $\begin{array}{l}\text { Mode of } \\
\text { Detection }\end{array}$ & $\begin{array}{l}\text { Self-Reported Co-morbidities/ Treat } \\
\text { ment Complications }\end{array}$ \\
\hline$\overline{1 \star}$ & $M, 70-74$ & Bowel & GP consult & 20 years & Prostate & Incidental & Atrial fibrillation, B12 deficiency \\
\hline 2 & F / 65-69 & Bowel & Incidental & 19 years & Breast & Nurse Consult & $\begin{array}{l}\text { lleostomy problems for } 7 \text { yearst, } C \text {. } \\
\text { difficile }\end{array}$ \\
\hline 3 & $F / 40-44$ & Cervical & Screening & 15 years & Breast & GP consult & RTx damage to bowel, early menopause \\
\hline 4 & $\begin{array}{l}M / 60- \\
64\end{array}$ & Kidney & GP consult & 24 years & Prostate & GP consult & Cirrhosis, E. coli \\
\hline 5 & F / 60-64 & Melanoma & GP consult & 16 years & Bowel & GP consult & High blood pressure \\
\hline 6 & $\mathrm{~F} / 70-74$ & Breast & GP consult & 3 years & Bowel & Screening & High blood pressure, seroma \\
\hline $7(8)$ & F / 70-74 & Breast & Incidental & 34 years & Bowel & GP consult & Peripheral neuropathy, asthma \\
\hline $8(9)$ & $F / 65-69$ & Pancreatic & GP consult & 10 years & Breast & Screening & Chronic fatigue syndrome, fibromyalgia \\
\hline $9(11)$ & $\mathrm{F} / 70-74$ & Breast & Screening & 7 years & Lung & GP non-cancer & Osteoporosis \\
\hline 10(13) & $F / 60-64$ & Endometrial & GP consult & 20 years & Colorectal & GP consult & RTx damage, bladder problems, MRSA \\
\hline $11(14)$ & $F / 60-64$ & Lymphoma & GP consult & 9 years & Lung & Incidental - via FPC & Arthritis \\
\hline $12(15)$ & $\begin{array}{l}M / 70- \\
74\end{array}$ & Larnyx & Incidental & 3 years & Prostate & GP consult & Back pain \\
\hline $13(16)$ & $\begin{array}{l}M / 75- \\
79\end{array}$ & Prostate & $\begin{array}{l}\text { Diabetes check- } \\
\text { up }\end{array}$ & 1 year & Lung & Incidental - via FPC & Diabetes, Macular degeneration \\
\hline $14(17)$ & $F / 75-79$ & $\mathrm{NHL}$ & Incidental & 5 years & Bowel & $\begin{array}{l}\text { Secondary care } \\
\text { consult }\end{array}$ & Heart condition \\
\hline $15(18)$ & $F / 80-84$ & $\mathrm{NHL}$ & Emergency & 5 years & Breast & Breast clinic & COPD \\
\hline 16(19) & $F / 60-64$ & Breast & Screening & 6 years & Colon & GP consult & $\begin{array}{l}\text { Underactive thyroid, peripheral } \\
\text { neuropathy }\end{array}$ \\
\hline $17(20)$ & $F / 60-64$ & Melanoma & GP consult & 21 years & Breast & Screening & Restless leg syndrome, IBS, depression \\
\hline $18(21)$ & $F / 45-49$ & Lymphoma & GP consult & 8 years & Breast & GP consult & Early menopause \\
\hline $19(22)$ & $\begin{array}{l}M / 65- \\
69\end{array}$ & Bladder & GP consult & 1 year & Prostate & Incidental - via FPC & $\begin{array}{l}\text { Diabetes, high blood pressure, high } \\
\text { cholesterol }\end{array}$ \\
\hline $20(23)$ & $F / 50-54$ & Melanoma & GP consult & 22 years & $\begin{array}{l}\text { Breast, then } \\
\text { Thyroid }\end{array}$ & Incidental & Thyroid problems \\
\hline
\end{tabular}

ॠ Of 23 people interviewed, 20 met the final inclusion criteria

Table 2 Patient interviews: additional quotes

\begin{tabular}{|c|c|}
\hline Themes & Supporting quotes \\
\hline Awareness of SPC & $\begin{array}{l}\text { "Interviewer: Did anybody ever mention to you about the risk of a second primary cancer or was it ever on your mind...? } \\
\text { P16: Never, no, no, I didn't think at all. "P13 } \\
\text { "I just completely forgot. [...], It's because of having no problems with the...after the first one that I just forgot all about it, I } \\
\text { really did." P14 }\end{array}$ \\
\hline $\begin{array}{l}\text { Symptom appraisal and } \\
\text { help-seeking }\end{array}$ & $\begin{array}{l}\text { "...Very tired, [...] I'm sitting at nine o'clock sleeping, and I thought this is not normal. So, I went to see my GP and they } \\
\text { took blood tests and then sent me for an X-ray, and that's when they discovered that I had a tumour in my lung." P1 } \\
\text { "I'm probably less inclined to just sit on } \\
\text { something and not go to the GP, as a result." } \\
\text { P18 }\end{array}$ \\
\hline $\begin{array}{l}\text { Pathways to diagnosis of } \\
\text { SPC }\end{array}$ & $\begin{array}{l}\text { "I will be absolutely frank, I never thought, oh goodness, that's the second time I've had cancer [...].[...]. That wasn't the } \\
\text { first thing that came to my mind. I would say it took me quite a long time to kind of clock that actually, that means I've } \\
\text { had cancer twice. It just wasn't top of my list of priorities to be perfectly honest." P5 }\end{array}$ \\
\hline $\begin{array}{l}\text { Navigating the healthcare } \\
\text { system }\end{array}$ & $\begin{array}{l}\text { "I go to that urology clinic, it's packed, it's absolutely mobbed. It's a really busy place [...]. When I went to the kidney clinic, } \\
\text { when I first got it, there was only me, you know, there wasn't a big queue or nothing." P4 }\end{array}$ \\
\hline Impact of SPC & $\begin{array}{l}\text { "Interviewer: Have they ever mentioned your first cancer, the melanoma or was that kind of never discussed? } \\
\text { P5: Not really discussed, I mean they knew, but it wasn't linked and nobody kind of majored on it." P5 }\end{array}$ \\
\hline Cumulative burden of SPC & "I thought, oh, no, here we go again." P8 \\
\hline
\end{tabular}




\section{Symptom appraisal and help-seeking}

Pathways to diagnosis described by participants have a marked similarity to those of a FPC.

In the case of those who had symptoms, participants reported that they responded to these by telling their GP or FPC consultant very quickly,

"..If this was a completely isolated, never had breast cancer before, I think I would have reacted the same way. I think I would have had that feeling of, something's not quite right here." P16

Participants also reported similar barriers and facilitators to those reported elsewhere in relation to pathways to diagnosis of a FPC, including issues such as normalising symptoms (e.g. attributing them to age or other ongoing comorbidities), work demands, masculine identity, and being encouraged by family members to seek help,

"But, men don't bother as much as, [...] I don't think." P1

There is a suggestion in the data that the help-seeking interval in the pathway to diagnosis may have been expedited as a result of their previous cancer. A number of participants reported, on reflection, a quick and sometimes urgent response in seeking advice from a HCP because of their previous cancer diagnosis,

"The last thing with my history is to leave it." P2

Similarly, some participants could have had their helpseeking and diagnostic intervals expedited by seeking help when at an FPC appointment,

"I noticed the lump. And I was due to see the nurse a few days later to take bloods. And I said to her, look what do you think? And she said, I think you should be seeing the doctor. [...] It was a doctor I'd never met before [...] But she said, right I'm referring you straight to the breast clinic at the [HOSPITAL]." P2

And while overall participants suggest that first primary cancers were not taken into consideration, some participants perceived that it did influence their care second time around,

"I think because I've had cancer before that when I get appointments in the hospital they're pretty quick." P4

\section{Pathways to diagnosis of SPC}

Routes to diagnosis varied among participants, with roughly half of diagnoses as a result of a GP referral following primary care attendance (see 'Mode of Detection', Table 1). The remaining half were picked up via screening or in secondary care whilst attending for follow-up of the FPC, both in the presence and absence of symptoms.

Participants could be roughly divided into two groups in the lead up to their SPC diagnoses. The first describe a fairly direct and uncomplicated path between one cancer diagnosis and another, often with many years between diagnoses and no lasting effects of their FPC following successful treatment,

"So I reacted quite quickly and I got an appointment with my GP and my GP was excellent. They did an internal [...] and she sent me for an urgent colonoscopy and I got that the following week." P16

For this group, the first cancer is reported as something in the past that was treated and doesn't have a lasting physical impact on their lives. The second cancer has come as a shock and was not expected.

For the second group of patients, the route between diagnoses was less straightforward and people were often dealing with recurrences, long-term side effects of first cancer treatment (e.g. stoma) or significantly disabling comorbid conditions,

"I didn't have time to worry about it 'cause it was always... my ileostomy [as a result of first primary bowel cancer] that takes over. And I have to just live my life to keep that working properly without worrying whether my breast cancer is going to come back again or not." P2

This group of patients is more likely to be in regular contact with healthcare services for ongoing treatment and review. While still unexpected and unwanted, the impact of the SPC can be considered to have had less of an impact on already turbulent circumstances.

\section{Navigating the healthcare system}

Previous experience of cancer did mean that participants knew, to a degree, what to expect and, in many cases, found the practical element easier second time around. People were more familiar with the process and navigating the health care system,

"But as I say, I think because of previous experiences and knowing the system and everything, I was able to just rationalise it pretty quickly and say, this is stupid. [...] I could apply colorectal to the problem, but obviously it wasn't exactly the same. But it gave me, sort of, insight and, you know...so that I wasn't so worried [...]." P2 
Respondents also observed changes in health care services, contrasting their two experiences of cancer, particularly when a long time had elapsed between diagnoses. While acknowledging that treatment and technological advances had been made, people perceived a busier, resource-constrained environment, with more pressure on staff to meet demands. They described crowded waiting rooms, longer waiting times and difficulties getting appointments in primary care,

"I feel really disappointed [...] I think it's just changing times, isn't it? [...] When I was going through all the pancreas things, for a long time after, my GP was amazing. She insisted I went to see her. [...] This GP I've got now hasn't even acknowledged that I've had breast cancer." $\mathbf{P 8}$

While participants praised the NHS and the quality of interpersonal care, they suggested that overall quality of care has suffered as a result of the demand on services, harking back to a time when there was better communication and good continuity of care.

\section{Impact of SPC}

The impact of a second primary cancer varied according to time between and since diagnoses; type, stage and severity of cancer; symptoms experienced; and treatment and side effects. The impact of an early stage cancer treated through surgery alone was less than that of chemotherapy and radiotherapy, and with long term consequences of treatment. For participant 14, not having to go through chemotherapy for his second cancer lessened the impact on his life considerably, despite having to live with a stoma,

"They operated the next day, and they took out a tumour which turned out to be a Dukes' A. [...] I convalesced for about two weeks and then I went back to work. [...] It was just straightforward, in for the operation, and I had a stoma, and it wasn't too bad, you know. It wasn't too bad because I never had chemo, this time." P14

The perceived relevance of FPC on SPC diagnosis varied between patients. Patients reported viewing their cancer diagnoses as separate events, interpreting their relevance to each other in the biological sense of having cancer in two different anatomical areas. However, the emotional relevance of each diagnosis was discussed,

"No, they're separate events, definitely. I definitely feel they're separate events but I still feel...I still worry about the pancreatic cancer. That's never, ever left me, that worrying about that. Yes, I would say I am worried about the breast cancer but, yes, it's two different worries, isn't it?" P8

Most patients report no mention of their previous cancer diagnosis by HCPs during their SPC journey; the patients were often the first to raise the issue.

However, the impact on daily life differed from considerations of the psychological impact of having cancer twice, which could not always be accounted for in the same way.

Cumulative emotional burden of a SPC In some respects, the emotional experience of a second cancer was similar to that of the first: the shock of diagnosis, struggling to make sense of what was happening, fear of recurrence and associated distress and worry,

"No, it's still just a massive blow when you're told and you still go through the same shock, horror, why me, and surely this can't be happening, not for a second time." P15

Participants appeared to use similar approaches to coping and adjustment through narratives of luck, hope and upward social comparison ("Other people are dying with it so I am lucky in a way" P4). However, there is evidence that going through cancer a second time added to the emotional burden of distress, worry and fear related to a cancer diagnosis.

"I thought, you know, you're quite blasé about it, you're not expecting to get a second one. That really takes the wind from you. [...] Quite devastating." P10

The findings suggest that previous experience of cancer heightens the long term emotional impact and amplifies the fear of recurrence.

"It does make you more aware of everything, you know. [...] It does... which I wasn't a worried person before, and it does make me more, everything now, oh gosh, what's this, you know." P6

It is also important to consider the emotional and psychological impact on family members in addition to the patients themselves. This is something that was raised by a number of participants,

"I try to protect them from it because I felt that they'd had enough. Yes, in some ways I feel like it's been...if this had been the first time...this second cancer had been the first time I had had 
cancer, I think that everybody's attitudes would be a lot different." P8

Fear of a third primary cancer A unique concern that builds on fear of recurrence commonly experienced by people who have experienced SPC is the fear of a third primary cancer. A number of participants voiced worries that if they could be unlucky enough to have cancer twice, they were aware that it could happen a third time, adding to their distress and anxiety,

"No. I mean, it's made me think about it now, now that I know, you know, I'm maybe a bit paranoid if you like, oh, I've had it twice, is it going to come back again, you know." P17

\section{GP interviews}

Seven GPs were interviewed, coming from a range of practice sizes and locations, including one female and six male GPs, and with varying levels of practice experience ranging from 3 to 25 years (see Table 3 ). The key findings from the GP interviews relate to awareness of and detection of SPC as reported below.

\section{Experience and knowledge of SPC}

GPs interviewed perceived SPCs as very rare and described never before or rarely encountering them in their clinical practice. Their focus was more likely to be on recurrence of an FPC,

"First we would probably think, is this a recurrence of the primary cancer [..], rather than a new diagnosis of another type of cancer." GP6, 6-10 years' experience

GPs reported not always knowing about the previous cancer. Time constraints, lack of continuity of care and time since the previous diagnosis often meant the FPC wasn't coded on their electronic record or the GP didn't have time to read it prior to consultation. While GPs felt they should know, it wasn't always the case, and the onus was often on the patient to bring it up.
"I would say it's very rare. I mean we might not even identify that they've had a previous cancer; it might not be relevant." GP 1, Under 5 years' experience

GPs reported that SPCs were not something they generally thought about (although time between diagnoses influenced this), or discussed the relative risk of with their patients. One GP considered that it was something they perhaps should be more aware of,

"It's just a little lightbulb moment for everybody and, I guess, raising awareness of it... if nobody says anything out loud then it maybe just doesn't occur to a lot of us." GP2, 21-25 years' experience

\section{Decision-making and referrals}

Similar to the findings from patient interviews, GPs described their decision-making around suspicion of cancer and referral as very similar to those of a first cancer. As with patient reports, SPCs are considered as unrelated to first primaries. GPs report that they respond to symptoms (particularly red flag symptoms) and make referral decisions accordingly,

\section{"I mean hopefully we refer people all fairly urgently" GP 7, 31-35 years' experience}

\section{"So it's more decided on presenting symptoms rather than what happened in the past." GP3, unknown experience}

However, one GP discusses individual variation and the distinction between biological and psychosocial impact of experiencing cancer for a second time; thus recognising the importance of acknowledging previous experience of cancer,

"I mean I think the two are probably related; I think they have the same sort of impact upon people's kind of psyche and things. So I mean I wouldn't necessarily associate the causality between the two of them, but I think from the patient's perspective, they've got

Table 3 GP Characteristics

\begin{tabular}{lll}
\hline GP identifier & Years' experience & Health Board/ relevant practice characteristics \\
\hline GP 1 & Under 5 years & Lothian, large practice, 6 GPs \\
GP 2 & $21-25$ years & Tayside, large urban practice \\
GP 3 & Unknown & Lothian, large semi-rural practice \\
GP 4 & $16-20$ years & Lothian, small, semi-rural, some deprivation. \\
GP 5 & $21-25$ years & Lothian, urban practice \\
GP 6 & $6-10$ years & Tayside, small rural practice \\
GP 7 & $31-35$ years & Borders, mid-size practice, semi-rural \\
\hline
\end{tabular}


cancer, it doesn't really matter whether it's one or two." GP5, 21-25 years' experience

The same issues arise as around the challenges of diagnosing first cancers in primary care, particularly when patients are frequent attenders or have multimorbidity clouding their cancer symptoms and in a resource constrained environment with competing priorities for patient care. Access to investigations and secondary care were also prevailing issues among interviewees.

\section{Discussion}

\section{Summary of findings}

This study reports the views and experiences of patients with SPC and their GPs, examining whether having previous first-hand experience of cancer influences one's subsequent pathway to diagnosis. Patient participants reported that they hadn't thought about getting a second, different cancer. Their symptom appraisal and helpseeking patterns were very similar to those for FPC, but with some suggestion that having a previous cancer did influence their decision-making. Patient experiences were varied, reflecting different cancer types, stages and severity of disease, and time between diagnoses. People had their second cancer detected in both primary and secondary care, both in response to and in the absence of symptoms, prompted by their help-seeking or an incidental finding. These incidental diagnoses are of interest, considering these cancers may not otherwise have been detected at this time and it is possible patients may not have consulted with symptoms, lengthening the patient interval prior to referral and diagnosis. However, participants do not explicitly refer to whether they felt being 'in the system' for follow-up made a difference.

Previous practical experience of navigating the health care system appeared to lessen anxiety as a result of familiarity. However, the psychological burden of SPC appeared to have a cumulative effect on people's emotional responses, especially where treatment was more invasive and had a bigger impact on people's lives, including those of loved ones. Moreover, knowledge of SPC raised concerns of the risk of third primary cancer, despite this risk being minimal.

GP accounts of diagnosing second cancers echo those of patients in reporting low awareness and a similar response to that of symptoms of FPC. GPs stated that they did not think of SPCs before receiving the study pack and were more vigilant for recurrence than SPC. However, they responded to red flag symptoms in the same way as they would for FPC. SPC detection is one challenge of many in the current climate of primary care.

\section{Comparison with existing literature and theory}

Few qualitative studies report experiences of SPC. Shin and colleagues in Korea have explored patient and oncologist perspectives on SPC surveillance and describe very similar narratives on rarity and lack of awareness $[5,24]$. However, past experience is likely to be more embodied and the influence of a previous cancer on people's behaviour more complex to tease out.

There are a number of barriers and facilitators to consider in terms of factors influencing help-seeking behaviour on the pathway to diagnosis. Previous experience has been highlighted as a factor influencing symptom appraisal and help-seeking in the Pathways to Treatment model [14]. Having prior, personal, experience of cancer appears to emphasise the role of this factor. Participants in our study may be more aware of cancer and early detection as a result of their treatment and conversations with specialists, as well as public health campaigns. However, fear of the known and resulting avoidance has been identified as a barrier to help-seeking elsewhere in the literature [25]. Nevertheless, patients in this study did allude to the fact that they were less likely to 'sit on things' due to their past experiences. It is worth noting that this participant group were people who had mostly been successfully treated for a previous cancer and most did not have advanced disease; responding more quickly to symptoms may therefore not apply to those with more advanced illness. Previous experience of cancer and moving through the healthcare system may impact on speed and likelihood of responding to symptoms, and there is some evidence in our data to support this claim, but more detailed exploration of this aspect of health behaviour is required. We would suggest that findings on diagnostic intervals be interpreted in the context of this group of interviewees and transferability to the average patient with SPC should be done with caution. Further large scale data is needed to compare diagnostic intervals between first and second and subsequent primary cancers.

The role of procedural knowledge (gained through experience of navigating the health care system) in lessening distress resonates with the information literature e.g. [26]. Having acquired general knowledge of how departments work and what to expect from surgery and recovery through past experience, albeit for a different cancer, embeds information and removes the uncertainty associated with anxiety and distress [27]. While past experience does not appear to wholly take away the shock and distress of SPC diagnosis, it may moderate it.

GP interviews suggest that their suspicions of cancer are no different for second primaries than for first cancers. They report responding to alarm symptoms as the primary indicator prompting referral for investigations, similar to other studies focused on early detection in 
primary care [28]. The role of a previous cancer appears to be minimal in the present study; yet it has been highlighted as key, along with presenting symptoms, in increasing suspicion of cancer in a survey with Norwegian GPs [29]. GPs discussed the challenges of diagnosing cancer in primary care - such as lack of resources, vague symptoms and comorbidities - as described in other studies [30,31]. However, in contrast to other studies, patients in this study did not report long delays and multiple consultations prior to second diagnosis [32], with potential implications for patient outcomes [33]. The focus on reported symptoms suggests that current research and interventions to understand, improve and support GP decision-making and referrals, as well as tackling psychological barriers to patient access to healthcare, are also relevant to early detection of SPC, as reported elsewhere [34-38]. These findings suggest that previous first-hand experience of cancer has a nuanced role in the decision-making process and there is scope for its addition to existing models of patient behaviour.

Cancer, whether it be a first or second diagnosis, appears to have a greater impact for participants if it brings more symptoms, more invasive treatment and limitations on functionality as a result of the lasting effects of surgery, chemotherapy and radiotherapy. These are the hallmarks of the cancer journey and embed cancer patienthood more forcefully, with a greater degree of disruption to daily life and personal identity or 'biographical disruption', for the patient and their family, and the quest for a new normal [29, 39-41]. The level of disruption, when also hit with a second cancer and potentially comorbid conditions as well, is heightened, though there may be scope for 'procedural knowledge' to moderate distress.

\section{Implications for research and practice}

There are implications, therefore, for people's ability to process the cumulative emotional burden and adjust to their illness and personal identity. Patients and GPs reported that previous cancers did not feature in discussions of their most recent cancer, but the emotional impact of previous experience was pronounced. While a previous cancer may not be significant in terms of diagnosing subsequent cancers (apart from known treatment-related or genetic links), it is clear that acknowledgement and discussion of past experiences and future risks holds psychological significance for patients' subsequent coping and adjustment [3]. It is necessary, therefore, to consider the role of this conversation in survivorship care provided in primary care spaces $[15,17,18]$.

We recommend the following: The risks of SPC should be sensitively communicated to cancer survivors; psychological support should be offered alongside conversations of risk and fear of recurrence to manage the emotional impact of a second primary cancer for patients and their families; SPC can be incorporated into the 'past experience' dimension of the Pathways to Treatment model to understand the journey to diagnosis of SPC; and existing efforts to detect cancer at an early stage and improve patient outcomes can be applied to SPC in their current form.

\section{Strengths and limitations of the study}

This study provides unique insights to the experiences of people who have been diagnosed with cancer for a second time, and for the GPs diagnosing them. This rich data can help to unpick the behavioural aspects of the pathway to diagnosis of SPC, to complement the body of evidence presenting incidence, risk and survival. This study provides some interesting findings to a group of early detection researchers expecting to find differences in the way patients and professionals respond to symptoms of an SPC. In fact, the pathways are very similar, providing important evidence for early diagnosis research.

Patient interviews come from a self-selecting group of invited participants who may have above-average health; long-term survivors are more likely to be recruited in studies such as this. While this study provides important evidence that is transferable to those who have survived a first cancer and are doing well, we may be missing the voice of those with advanced and end of life disease, for whom the pathways to diagnosis may be very different and/or difficult. Participants' experiences are also captured relatively soon after diagnosis and so a longitudinal design may have offered different insights over time. Finally, this interview study is conducted with those who self-selected to take part and therefore findings cannot be assumed to be transferable to the broader population of cancer survivors; caution in interpreting the results is warranted. Abel and colleagues have explored characteristics of responders and the role of non-response in UK-wide cancer patient experience survey [42].

Recruitment of case-linked GP interviews proved challenging and resource issues resulted in a small number of GP interviews being achieved. While worthwhile findings with strong conformity have been obtained, findings are limited in their transferability and should be interpreted in the wider context of early diagnosis and primary care research.

\section{Conclusions}

Awareness of the risk of second primary cancer is low among cancer patients and GPs involved in cancer surveillance. However, synchronous reports from patients 
and GPs about symptom appraisal, help-seeking and referral for suspicions of cancer being very similar for first and second primary cancers suggest that current efforts to expedite diagnosis of cancer are as applicable to SPC as to FPC. Evidence to suggest a cumulative psychological burden of second primary cancer and fear of third primary highlight the need for past experiences of cancer to be part of the conversation and risks of subsequent cancers sensitively discussed.

\section{Abbreviations}

NCJDRSU: National Creutzfeldt-Jakob Disease Research and Surveillance Unit: eDRIS: Electronic Data Research and Innovation Service; NHS: National Health Service; GP: General Practitioner; FPC: First Primary Cancer; SPC: Second Primary Cancer; HCP: Healthcare provider

\section{Supplementary Information}

The online version contains supplementary material available at https://doi. org/10.1186/s12885-021-08238-0

Additional file 1.

Additional file 2.

\section{Acknowledgements}

With thanks to Florence Kyalo from eDRIS for her assistance with recruiting participants for this study and all those who took part.

\section{Authors' contributions}

$C C, D C, K B, D H B$ and $D W$ devised this study. $A B$ and $L K$ had input to the study design and $A B$ carried out the research interviews. RD, DC and CC analysed the transcripts and RD drafted a report of the findings and all authors commented on the analysis. DC drafted this manuscript and all authors have commented on revised versions. The author(s) read and approved the final manuscript.

\section{Funding}

This study was funded by Cancer Research UK, grant number C12357/ A21326. The funders did not play any role in the design of the study, the collection, analysis, and interpretation of data, or in writing the manuscript.

\section{Availability of data and materials}

Data has not been deposited in a public repository. Anonymised data is available on reasonable request to the authors.

\section{Declarations}

\section{Ethics approval and consent to participate}

This study was approved by the NHS East of Scotland REC on 1st February 2017. Participants signed a consent form giving permission for interviews to be recorded and analysed for research purposes.

\section{Consent for publication}

Consent was given for anonymised data to be included in this publication.

\section{Competing interests}

The authors declare no conflict of interest.

\section{Author details}

${ }^{1}$ Usher Institute of Population Health Sciences, Medical School, University of Edinburgh, Teviot Place, Edinburgh EH8 9AG, UK. Institute of Applied Health Research, University of Birmingham, Edgbaston, Birmingham B15 2TT, UK. ${ }^{3}$ Population Health and Genomics, School of Medicine, Ninewells Hospital, University of Dundee, Dundee DD1 9SY, UK. ${ }^{4}$ NCJDRSU, Western General Hospital, Crewe Road South, Edinburgh EH4 2XU, UK.
Received: 21 August 2020 Accepted: 22 April 2021

Published online: 03 May 2021

\section{References}

1. Cancer Research UK. Available from: https://www.cancerresearchuk.org/hea Ith-professional/cancer-statistics/survival. [cited 21.01.2020].

2. Wood ME, Vogel V, Ng A, Foxhall L, Goodwin P, Travis LB. Second malignant neoplasms: assessment and strategies for risk reduction. J Clin Oncol. 2012; 30(30):3734-45. https://doi.org/10.1200/JCO.2012.41.8681.

3. Deimling GT, Bowman KF, Sterns S, Wagner LJ, Kahana B. Cancer-related health worries and psychological distress in older adult, long term cancer survivors. Psycho-oncology. 2006;15(4):306-20. https://doi.org/10.1002/pon. 955.

4. Wilkins KL, Woodgate RL. Life after cancer: living with risk. Cancer Nurs. 2011;34(6):487-94. https://doi.org/10.1097/NCC.0b013e318208f2b3.

5. Shin DW, Baik YJ, Kim YW, Oh JH, Chung KW, Kim SW, et al. Knowledge, attitudes, and practice on second primary cancer screening among cancer survivors: a qualitative study. Patient Educ Couns. 2011;85(1):74-8. https:// doi.org/10.1016/j.pec.2010.09.015.

6. Hayat MJ, Howlader N, Reichman ME, Edwards BK. Cancer statistics, trends, and multiple primary cancer analyses from the surveillance, epidemiology, and end results (SEER) program. Oncologist. 2007;12(1):20-37. https://doi. org/10.1634/theoncologist.12-1-20.

7. Phipps Al, Chan AT, Ogino S. Anatomic subsite of primary colorectal cancer and subsequent risk and distribution of second cancers. Cancer. 2013; 119(17):3140-7. https://doi.org/10.1002/cncr.28076.

8. Youlden DR, Baade PD. The relative risk of second primary cancers in Queensland, Australia: a retrospective cohort study. BMC Cancer. 2011;11:83.

9. Molina-Montes E, Requena M, Sánchez-Cantalejo E, Fernández MF, ArroyoMorales M, Espín J, et al. Risk of second cancers cancer after a first primary breast cancer: a systematic review and meta-analysis. Gynaecol Oncol. 2015; 136(1):158-71. https://doi.org/10.1016/j.ygyno.2014.10.029.

10. Coyte A, Morrison DS, McLoone P. Second primary cancer risk - the impact of applying different definitions of multiple primaries: results from a retrospective population-based cancer registry study. BMC Cancer. 2014; 14(1):272. https://doi.org/10.1186/1471-2407-14-272.

11. Travis LB. Cancer survivorship--genetic susceptibility and second primary cancers: research strategies and recommendations. J Natl Cancer Inst. 2006; 98(1):15-25. https://doi.org/10.1093/jnci/djj001.

12. Oeffinger KC, Baxi SS, Novetsky FD. Solid tumor second primary neoplasms: who is at risk, what can we do? Sem Oncol. 2013:40(6):676-89. https://doi. org/10.1053/.jseminoncol.2013.09.012.

13. Ries LAG, Eisner MP, Kosary CL, et al. SEER Cancer Statistics Review, 19752000. Bethesda: National Cancer Institute; 2003.

14. Walter F, Webster A, Scott S, Emery J. The Andersen model of total patient delay: a systematic review of its application in cancer diagnosis. J Health Serv ResPolicy. 2012;17(2):110-8. https://doi.org/10.1258/jhsrp.2011.010113.

15. Aziz NM. Cancer survivorship research: state of knowledge, challenges and opportunities. Acta Oncologia. 2007;46(4):417-32. https://doi.org/10.1080/02 841860701367878.

16. Watson EK, et al. Views of health professionals on the role of primary care in the follow-up of men with prostate cancer. Fam Pract. 2011;28(6):647-54. https://doi.org/10.1093/fampra/cmr034.

17. Khan NF, Watson EK, Rose PW, et al. Primary care consultation behaviours of long-term, adult survivors of cancer in the UK. Br J Gen Pract. 2011;61(584): 197-9. https://doi.org/10.3399/bjgp11X561195

18. Watson EK, Rose PW, Neal RD, Hulbert-Williams N, Donnelly P, Hubbard G, et al. Personalised cancer follow-up: risk stratification, needs assessment or both? Br J Cancer. 2012:106(1):1-5. https://doi.org/10.1038/bic.2011.535.

19. Reeve J, Blakeman T, Freeman GK, Green LA, James PA, Lucassen P, et al. Generalist solutions to complex problems: generating practice-based evidence--the example of managing multi-morbidity. BMC Fam Pract. 2013; 14(1):112. https://doi.org/10.1186/1471-2296-14-112.

20. Scottish Government, Better Cancer Care, October 2008; https://www.gov. scot/binaries/content/documents/govscot/publications/strategy-plan/2008/1 0/better-cancer-care-action-plan/documents/0067458-pdf/0067458-pdf/ govscot\%3Adocument/0067458.pdf, Accessed 03 Mar 2020.

21. Department of Health and Human Services Department of Health and Human Services. U.S. Second primary cancer. National Cancer Institute. https://www.cancer.gov/publications/dictionaries/cancer-terms?cdrid=46658. Accessed 1 Aug 2020. 
22. Braun V, Clarke V. Using thematic analysis in psychology. Qual Res Psychol. 2006;3(2):77-101. https://doi.org/10.1191/1478088706qp063oa.

23. Varpio L, Ajjawi R, Monrouxe LV, O'Brien BC, Rees CE. Shedding the cobra effect: problematising thematic emergence, triangulation, saturation and member checking. Med Educ. 2017;51(1):40-50. https://doi.org/10.1111/ medu.13124.

24. Shin DW, Kim YW, Baek YJ, Mo HN, Choi JY, Cho JH. Oncologists experience with second primary cancer screening: current practices and barriers and potential solutions. Asia Pac J Cancer Prev. 2012;13(2):671-6. https://doi. org/10.7314/APJCP.2012.13.2.671.

25. Smith LK, Pope C, Botha J. Patients' help-seeking experiences and delay in cancer presentation: a qualitative synthesis. Lancet. 2005;366:825-31. https:// doi.org/10.1016/S0140-6736(05)67030-4.

26. Jones RB, Pearson J, Cawsey AJ, Bental D, Barrett A, White J, et al. Effect of different forms of information produced for cancer patients on their use of the information, social support, and anxiety: randomised trial. BMJ. 2006; 332(7547):942-8. https://doi.org/10.1136/bmj.38807.571042.68.

27. Cavers D, Hacking B, Erridge SE, et al. Social, psychological and existential well-being in patients with glioma and their caregivers: a qualitative study. Can Med Assoc J. 2012;184(7):E373-82. https://doi.org/10.1503/cmaj.111622.

28. Johansen M, Holtedahl KA, Rudebeck CE. How does the thought of cancer arise in general practice consultation? Interviews with GPs. Scand J Prim Health Care. 2012;30(3):135-40. https://doi.org/10.3109/02813432.2012. 688701.

29. Scheel Bl, Ingebrigtsen ST, Thorsen T, Holtedahl K. Cancer suspicion in general practice: the role of symptoms and patient characteristics, and their association with subsequent cancer. Br J Gen Pract. 2013;63(614):e627-35. https://doi.org/10.3399/bjgp13X671614.

30. Rubin $\mathrm{G}$, Berensden $\mathrm{A}$, Crawford $\mathrm{M}$, et al. The expanding role of primary care in cancer control. Lancet Oncol. 2015;16(12):1231-7. https://doi.org/10.1 016/S1470-2045(15)00205-3.

31. Green T, Atkin K, Macleod U. Cancer detection in primary care: insights from general practitioners. Br J Cancer. 2015;112(Suppl 1):S41-9. https://doi.org/1 $0.1038 /$ bjc.2015.41

32. Lyratzopoulos G, Neal RD, Barbiere JM, Rubin GP, Abel GA. Variation in number of general practitioner consultations before hospital referral for cancer: findings from the 2010 National Cancer Patient Experience Survey in England. Lancet Oncol. 2012;13(4):353-65. https://doi.org/10.1016/S1470-204 5(12)70041-4.

33. Neal RD, Tharmanathan P, France B, Din NU, Cotton S, Fallon-Ferguson J, et al. Is increased time to diagnosis and treatment in symptomatic cancer associated with poorer outcomes? Systematic review. Br J Cancer. 2015; 112(Suppl. 1):S92-S107. https://doi.org/10.1038/bjc.2015.48.

34. Hamilton W. The CAPER studies: five case-control studies aimed at identifying the risk of cancer in symptomatic primary care patients. $\mathrm{Br} \mathrm{J}$ Cancer. 2009;101 (Suppl. 2):S80-6. https://doi.org/10.1038/sj.bjc.6605396.

35. Walter FM, Thompson MJ, Wellwood I, Abel GA, Hamilton W, Johnson M, et al. Evaluating diagnostic strategies for early detection of cancer: the CanTest framework. BMC Cancer. 2019;19(1):586. https://doi.org/10.1186/s12 885-019-5746-6.

36. Austoker J, Bankhead C, Forbes LL, Atkins L, Martin F, Robb K, et al. Interventions to promote cancer awareness and early detection: systematic review. Br J Cancer. 2009;101(S2):S31-9. https://doi.org/10.1038/sj.bjc.6605388.

37. Wardle J, Robb K, Vernon S, Waller J. Screening for prevention and early detection of cancer. Am Psychol. 2015;70(2):119-33. https://doi.org/10.103 7/a0037357.

38. Kummer S, Walter F, Chilcot J, Emery J, Sutton S, Scott S. Do cognitive heuristics underpin symptom appraisal for symptoms of cancer?: a secondary qualitative analysis across seven cancers. Psycho-oncology. 2019. https://doi.org/10.1002/pon.5049.

39. Bury M. Chronic illness as biographical disruption. Sociol Health Illness. 1982; 4(2):167-82. https://doi.org/10.1111/1467-9566.ep11339939.

40. Reeve J, Lloyd-Williams M, Payne S, Dowrick C. Revisiting biographical disruption: exploring individual embodied illness experience in people with terminal cancer. Health. 2010;14(2):178-95. https://doi.org/10.1177/13634593 09353298.

41. Hubbard G, Forbat L. Cancer as biographical disruption: constructions of living with cancer. Support Care Cancer. 2012;20(9):2033-40. https://doi. org/10.1007/s00520-011-1311-9.

42. Abel GA, Saunders CL, Lyratzopolouos G. Post-sampling mortality and nonresponse patterns in the English Cancer patient experience survey: implications for epidemiological studies based on surveys of cancer patients. Cancer Epidemiol. 2016;14:34-41. https://doi.org/10.1016/j.canep.2 015.12.010.

\section{Publisher's Note}

Springer Nature remains neutral with regard to jurisdictional claims in published maps and institutional affiliations.
Ready to submit your research? Choose BMC and benefit from:

- fast, convenient online submission

- thorough peer review by experienced researchers in your field

- rapid publication on acceptance

- support for research data, including large and complex data types

- gold Open Access which fosters wider collaboration and increased citations

- maximum visibility for your research: over $100 \mathrm{M}$ website views per year

At BMC, research is always in progress.

Learn more biomedcentral.com/submissions 